\title{
Preterm Labor and Treatment Efficacy-Safety
}

\author{
PREETI GURUNG ${ }^{* 1}$, SHIKHA THAKUR², DAVID PRADHAN3
}

With medical sciences on the verge of advancement, preterm labor still remains a bothersome issue in modern obstetrics. A few therapeutic agents that suppress uterine contractile activity have gained success up to some extent. Tocolytics are medications used to suppress premature labor. These drugs can decrease the strength and frequency of uterine contractions and help in delay the onset of labor but are not able to prolong pregnancy to full-term. Presently, the choice of a best tocolytic drug remains debatable. This review discusses efficacy and safety of various useful agents which have been used so far. Further clinical trials are required to select an effective, and most importantly, safe therapy for the threatened preterm labor.

KEYWORDS: Tocolytics, Calcium Channel Blockers, Preterm Labor

\section{INTRODUCTION}

Preterm labor is defined as delivery occurring between 22 and $36+6$ weeks of gestation, with gestational age determined based on the ist day of the last menstrual period and fetal scanning performed in the 1st trimester. ${ }^{1}$ About 15 million babies are born prematurely each year, and this number steadily increases. Complications of preterm labor are the leading cause of death in infants under 5 years of age. According to the $\mathrm{WHO}$, the rates of preterm labor range from 5 to $18 \%$ of the number of the newborns in 184 countries. $^{2}$ Clinical symptoms that determine the true onset of labor are the same regardless of gestational age and are manifested as structural changes in the cervix and the onset of regular labor activity. Cervical changes include dilatation of internal orifice, shortening, softening, and centralization of the cervix. Cervical changes in the started PL occur within several hours, which distinguishes them from the cervical ripening process, which occurs over days or even weeks. ${ }^{1}$

The criteria for diagnosing the threatened preterm labor are manifested as irregular pain in the lower abdomen and lumbar region. Uterine hypertonus, shortening of the cervix, and opening of the external orifice are objectively detected. The started preterm labor is accompanied by lower abdominal pain, recorded regular uterine activity, central position of the shortened, softened, and often dilated cervix, mucosal or mucosal-serous secretions from the genital tracts suggestive of cervical ripening. Amniotic fluid may discharge prematurely. In a few countries, nifedipine and atosiban are recommended as first-line tocolytic therapy. ${ }^{1}$ Nifedipine and atosiban have comparable efficacy in prolonging pregnancy for up to 7 days. Compared with $\beta$ agonists, nifedipine is associated with improved neonatal outcome, but long-term data are not available to date. A meta-analysis showed no significant differences between atosiban and nifedipine in prolonging pregnancy. However, atosiban was associated with fewer maternal side effects than nifedipine. ${ }^{3}$ The use of nifedipine and atosiban within 48 hours in pregnant women at risk of preterm labor is associated with similar perinatal outcomes. ${ }^{4}$ A study showed showed that infants born before 32 weeks of gestation after tocolytics use had a high incidence of craniocerebral injury. No significant differences were found in the organic brain lesion between neonates whose mothers received nifedipine and neonates who received atosiban. ${ }^{5}$ Compared with $\beta$-adrenergic agonists the use of atosiban was associated with a significantly lower incidence of adverse events such as tachycardia, palpitations, vomiting, headache, hyperglycemia, tremor, dyspnea, chest pain,

(C) Preeti Gurung et al. This is an open access article distributed under the terms of the Creative Commons Attribution License CC-BY-NC 4.o, which permits unrestricted use, distribution and reproduction in any medium, provided the use is not commercial and the original author(s) and source are cited. Submitted on: 16-Oct-2021; Accepted on: 23-Nov-2021 
hypokalemia, and fetal tachycardia. ${ }^{6}$ In another study, atosiban was found to be a more effective tocolytic than hexoprenaline in the treatment of threatened preterm labor. A study showed that atosiban prolonged pregnancy by 48 hours or more in $71.9 \%$ of pregnant women. ${ }^{7}$ In another study, the comparison of nifedipine and fenoterol showed the same latent period in both groups. More side effects were reported in the fenoterol group. The economic evaluation did not reveal a significant difference in cost savings between the groups receiving either drug. Neither clinical nor economic superiority of either of the two drugs was demonstrated in the study. ${ }^{8}$ A randomized study showed a difference between oral and sublingual use of nifedipine. The time required for tocolysis was significantly shorter with sublingual nifedipine. Sublingual nifedipine was also more effective than oral nifedipine in stopping preterm labor within 90 minutes. ${ }^{9}$ Other randomized study demonstrated the efficacy of nifedipine in combination with sildenafil citrate with fewer deliveries within 7 days of hospitalization and fewer admissions in neonatal intensive care units, fewer early preterm deliveries, and increased birth weights. ${ }^{10}$ Comparison of nifedipine with terbutaline in other study showed a similar tocolytic effect of the drugs. However, nifedipine was associated with fewer side effects. ${ }^{11}$

Atosiban is also preferred over $\beta$-adrenergic agonists and drugs with similar effects. The prolongation of pregnancy by 48 hours was significantly higher in the atosiban group than in the ritodrine group, while the prolongation of pregnancy by 7 days was similar in both groups. The incidence of side effects in pregnant women was higher in the ritodrine group than in the atosiban group, but the prevalence of abnormal fetal heart rhythm was not statistically significantly different. Both perinatal mortality and prevalence of neonatal asphyxia were significantly lower in the atosiban group. Perinatal mortality and prevalence of neonatal pneumonia were also lower in the atosiban group when using the drug at gestational age less than 28 weeks. Regardless of the drug initiation time, there were no significant differences between the atosiban and ritodrine groups in the cases of neonatal asphyxia, acute respiratory distress syndrome, neonatal craniocerebral injury, or neonatal sepsis. ${ }^{12}$ A randomized, controlled study compared the efficacy of the nicorandil, a potassium channel blocker, and nifedipine, a calcium channel blocker, for tocolysis in preterm labor. Nicorandil was comparable to nifedipine in terms of pregnancy prolongation by 48 hours, 7 days and up to 37 weeks of gestation. Nausea and vomiting, maternal tachycardia, and fetal tachycardia were significantly more common in women treated with nicorandil. Headaches were significantly more common in women treated with nifedipine. There was no difference in neonatal outcome between the two groups. ${ }^{13}$ To date, indomethacin remains a second line tocolytic, but studies have shown a low safety profile. A metaanalysis showed the probability of pregnancy prolongation by 48 hours was highest in prostaglandin inhibitors versus placebo, followed by magnesium sulfate, calcium channel blockers, $\beta$ adrenergic agonists, and atosiban. Compared to placebo, the side effects requiring drug switching were significantly higher for $\beta$-adrenergic agonists, magnesium sulfate, and calcium channel. ${ }^{14}$ Studies of progesterone use in successful tocolysis are controversial and require further investigation. Maintenance vaginal progesterone tocolysis is associated with significant prolongation of pregnancy and lower neonatal sepsis. ${ }^{15}$ Another study also showed benefits of vaginal progesterone in pregnancy prolongation after successful tocolysis with atosiban. ${ }^{16} \mathrm{~A}$ systematic review by showed that women treated with 17-alpha hydroxyprogesterone caproate had significantly later gestational age at delivery and higher neonatal weights compared to controls. Other secondary outcomes, including neonatal mortality, neonatal intensive care unit admission rate, neonatal respiratory distress syndrome, bronchopulmonary dysplasia, intraventricular hemorrhage, necrotizing enterocolitis, and neonatal sepsis, were similar in both groups. ${ }^{17}$ In contrast, other study showed that injections of 17-alpha-hydroxyprogesterone caproate did not significantly prolong pregnancy in women with preterm labor after tocolysis. ${ }^{18}$ Two studies demonstrated the efficacy of prolonged progesterone tocolysis compared to nifedipine with better neonatal outcomes and fewer side effects. ${ }^{19,20}$ A study conducted in India showed that oral micronized progesterone significantly prolonged pregnancy. ${ }^{21} \mathrm{~A}$ systematic review including 16 randomized controlled trials showed that the preterm labor rate at less than 37 weeks of gestation decreased and gestational age increased when women received progestogens compared to placebo or no treatment. $^{22}$ Another study showed that progesterone was ineffective in the prevention of $\mathrm{PL}$ after successful tocolysis. ${ }^{23}$ Both the development of new drugs for tocolysis and the study of 
combinations of the available tocolytics are promising. It is not clear whether a combination of tocolytic drugs in preterm labor is more effective in women and/or neonates because of the lack of large studies of combination tocolytic regimens. Further trials are needed before specific conclusions can be drawn about the use of combination tocolytic therapy in preterm labor.

\section{CONCLUSION}

The analysis of available literature showed that preterm labor is the leading cause of neonatal morbidity, mortality, and long-term consequences. Prevention and treatment of preterm labor remain a challenge in modern obstetrics. The accumulated domestic and foreign experience suggests that despite the increasing range of tocolytic agents, there are currently no more effective agents to suppress the contractility of the uterus than oxytocin receptor agonists and calcium channel blockers. As for neonatal outcomes, it is difficult to select the preferred drug because all tocolytics have a similar spectrum of outcomes for the fetus and newborn. Many studies suggest that clinicians should use a tocolytic that has produced the best results with the least adverse effects for the mother/newborn. It is necessary to continue clinical trials in order to select an effective, and most importantly safe, therapy for threatened preterm labor.

\section{REFERENCES}

1. Khodzhaeva ZS, Shmakov RG, Adamyan LV et al. Clinical recommendations. Preterm birth. M.; 2020. $42 \mathrm{p}$.

2. Vogel JP, Chawanpaiboon S, Moller AB, Watananirun K, Bonet M, Lumbiganon P. The global epidemiology of preterm birth. Best Pract. Res Clin Obstet Gynaecol 2018; 52: 3-12.

3. Ali AA, Sayed AK, El Sherif L, Loutfi GO, Ahmed AMM, Mohamed HB et al. Systematic review and meta-analysis of randomized controlled trials of atosiban versus nifedipine for inhibition of preterm labor. Int. J. Gynaecol Obstet 2019; 145(2): 139-48.

4. van Vliet EOG, Nijman TAJ, Schuit E, Heida KY, Opmeer BC, Kok $\mathrm{M}$ et al. Nifedipine versus atosiban for threatened preterm birth (APOSTEL III): a multicentre, randomised controlled trial. Lancet. 2016; 387(10033): 2117-24.

5. Nijman TAJ, Goedhart MM, Naaktgeboren CN, de Haan TR, Vijlbrief DC, Mol BW, et al. Effect of nifedipine and atosiban on perinatal brain injury: secondary analysis of the APOSTEL-III trial. Ultrasound Obstet. Gynecol. 2018; 51(6): 806-12.

6. Wex J, Connolly M, Rath W. Atosiban versus betamimetics in the treatment of preterm labour in Germany: an economic evaluation. BMC Pregnancy Childbirth. 2009; 9: 23.

7. Belousova VS, Strizhakov AN, Timokhina EV, Bogomazova IM, Pitskhelauri EG, Emelyanova ES. Premature birth: how to manage tocolysis? Obstetrics and gynecology. 2019; 6:102-7.

8. Valdes E, Salinas H, Toledo V, Lattes K, Cuellar E, Perucca $\mathrm{E}$ et al. Nifedipine versus fenoterol in the management of preterm labor: a randomized, multicenter clinical study. Gynecol. Obstet. Invest. 2012; 74(2): 109-15.

9. Leal-Junior CC, Amorim MMR, Souza GFA, Lima AKS, Souza ASR. Effectiveness of an oral versus sublingual loading dose of nifedipine for tocolysis. Int J.Gynaecol Obstet 2020; 148(3): 310-5.

10. Maher MA, Sayyed TM, El-Khadry SW. Nifedipine alone or combined with sildenafil citrate for management of threatened preterm labour: a randomised trial. BJOG. 2019; 126(6): 729-35.

11. Padovani TR, Guyatt G, Lopes LC. Nifedipine versus terbutaline, tocolytic effectiveness and maternal and neonatal adverse effects: a randomized, controlled pilot trial. Basic Clin Pharmacol Toxicol 2015; 116(3): 244-50.

12. Xu YJ, Ran LM, Zhai SS, Luo XH, Zhang YY, Zhou $\mathrm{ZY}$ et al. Evaluation of the efficacy of atosiban in pregnant women with threatened preterm labor associated with assisted reproductive technology. Eur Rev Med Pharmacol Sci 2016; 20(9): 1881-7.

13. Rezk M, Sayyed T, Masood A, Dawood R. Nicorandil vs nifedipine for the treatment of preterm labour: a randomized clinical trial. Eur J Obstet Gynecol Reprod Biol 2015; 195: 27-30

14. Haas DM, Caldwell DM, Kirkpatrick P, McIntosh JJ, Welton NJ. Tocolytic therapy for preterm delivery: systematic review and network meta-analysis. BMJ. 2012; 345: e6226.

15. Suhag A, Saccone G, Berghella V. Vaginal progesterone for maintenance tocolysis: a systematic review and meta-analysis of randomized trials. Am J Obstet Gynecol 2015; 213(4): 479-87.

16. Areia A, Fonseca E, Moura P. Progesterone use after successful treatment of threatened pre-term delivery. J Obstet Gynaecol 2013; 33(7): 678-81.

17. Saccone G, Suhag A, Berghella V. 17-alphahydroxyprogesterone caproate for maintenance tocolysis: a systematic review and metaanalysis of randomized trials. Am J Obstet Gynecol 2015; 213(1): 
16-22.

18. Rozenberg P, Chauveaud A, Deruelle P, Capelle $\mathrm{M}$, Winer $\mathrm{N}$ et al; Groupe De Recherche En Obstétrique et Gynécologie. Prevention of preterm delivery after successful tocolysis in preterm labor by 17 alpha-hydroxyprogesterone caproate: a randomized controlled trial. Am J Obstet Gynecol. 2012 Mar;206(3):206.e1-9.

19. Aggarwal A, Bagga R, Girish B, Kalra J, Kumar P. Effect of maintenance tocolysis with nifedipine in established preterm labour on pregnancy prolongation and neonatal outcome. J Obstet Gynaecol 2018; 38(2): 177-84.

20. Kamat S, Veena P, Rani R. Comparison of nifedipine and progesterone for maintenance tocolysis after arrested preterm labour. J Obstet Gynaecol 2014;34(4): 322-5.
21. Choudhary M, Suneja A, Vaid NB, Guleria K, Faridi MM. Maintenance tocolysis with oral micronized progesterone for prevention of preterm birth after arrested preterm labor. Int J Gynaecol Obstet. 2014; 126(1): 60-3.

22. Palacio M, Ronzoni S, Sбnchez-Ramos L, Murphy KE. Progestogens as maintenance treatment in arrested preterm labor: a systematic review and metaanalysis. Obstet. Gynecol. 2016; 128(5): 9891000 .

41. Wood S, Rabi Y, Tang S, Brant R, Ross S. Progesterone in women with arrested premature labor, a report of a randomised clinical trial and updated meta-analysis. BMC Pregnancy Childbirth. 2017; 17(1):258. 